\title{
A Model of Information Systems Success for Assessing the Effectiveness of Statistical Learning Tool on University Students Performance in Statistics
}

\author{
Zeinab Zaremohzzabieh ${ }^{* 1}$ \\ Bahaman Abu Samah ${ }^{1}$ \\ Jusang Bolong ${ }^{3}$ \\ Mahazan Muhammad 1 \\ Rusli Abdullah² \\ Jeffrey Lawrence D'Silva1 \\ Hayrol Azril Mohamed Shaffril ${ }^{1}$ \\ ${ }^{1}$ Institute for Social Science Studies, Universiti Putra Malaysia \\ ${ }^{2}$ Faculty of Computer Science, Universiti Putra Malaysia \\ ${ }^{3}$ Faculty of Modern Languages and Communication, Universiti Putra Malaysia \\ *Correspondence: Zeinab Zaremohzzabieh, Institute for Social Science Studies, Universiti Putra Malaysia \\ 43400 UPM Serdang, Selangor, Malaysia. Email: zeinabzaremohzzabieh@gmail.com
}

Doi:10.5901/mjss.2016.v7n2p271

\section{Abstract}

\begin{abstract}
The purpose of the study was to validate the DeLone and McLean Information systems (IS) success model to determine the effectiveness of statistical learning tool (SLT) in facilitating learning statistics among graduate students. In order to test the model, a quantitative method was employed such as distributing questionnaires. A total of 129 graduate students registered for statistics in social science course from selected faculties in Universiti Putra Malaysia were chosen based on stratified random sampling. In this study, structural equation modeling (SEM) which is a data analysis method was employed to provide the info of statistics performance through the analysis of direct and indirect effect. The results of the study demonstrated that service quality was the most influential variable in this model (followed by system quality), thus highlighting the importance of service quality for students' performance in statistics; nevertheless, the findings did not support the mediation of an intention to use and users' satisfaction. Implications of our findings will enable future researchers to continue studies on SLT on a broader basis of theoretical support.
\end{abstract}

Keywords: Information system success model, statistical learning tool, university students, and statistics performance

\section{Introduction}

Statistics courses are compulsory for most graduate students in universities across different field of study because it provides a relevant tool in statistical analysis. This importance emerge from the fact that nearly every graduate student enrolled are required to select at least one graduate-level course in statistics. Unfortunately, for many graduate students, statistics is the most challenging courses in their degree programmes. Mainly for students in social science fields who are comparatively weak in mathematics, they may encounter problems to calculate statistics manually, remember the stepby-step procedure in hypothesis testing, and interpret analysis results. Many studies have showed that many graduates experience a high degree of statistical anxiety when confronted with statistical ideas, problems, evaluative situations, issues, or statistical sites. Onwuegbuzie (1998) found that almost $80 \%$ of graduate students have a high level of statistical anxiety which is a major menace to the attainment of their degree programme. In fact, as a result of anxiety, graduate students often delay taking the required statistics courses. They may delay it until the last term which is not ideal. This suggested that many students view statistics as a less relevant or less significant component in their degree programmes, but just a persistent difficulty that they must overcome in order to graduate.

Undoubtedly, statistical learning tool (SLT) which uses technology can assist students in learning statistics as the 
supplementary tool for students in statistics class and helps reducing university students' anxiety about statistics. Now, using technologies as the learning tools in the classroom, teaching becomes an accessible platform for most institutions of higher education, because of its pedagogical approach to higher training. Many statisticians involved in the reformation for the improvement of statistics. According to Moore (1997), reformation of teaching statistics occurred due to the changes in content (i.e., less probability and more data analysis,), pedagogy (e.g., more active learning and fewer lectures), and technology (i.e., simulations and data analysis). Moore (1992) presented a set of interpretations to notify statistics instructors about the techniques and its new content. Many statisticians have recommended the ways to modify teaching methods and to incorporate technology (e.g., Rossman \& Chance, 2004). Early studies revealed that computers and statistical software have statistically facilitated graduate students on how to use statistics correctly and how to interpret the results of complicated statistical procedures (Yahaya \& et al., 2007). Marshall (2002) has found the evidence that technology helps spreading their reach and broadens the student's experience outside the classroom. He also mentioned that there is an essential part needs to understand the method achieves success, which includes teacher, learner, content, and setting in which the technology is utilised. For example, via statistical tools, graduate students are able to get the precise solutions with a high degree of confidence. There are many applications and procedures available that help in applying statistical approaches that include descriptive and inferential statistics.

However, there are different types of SLT technologies which can be utilised to sustain and enhance the teaching and learning environments. Nevertheless, inadequate information and information quality related to the infrastructure requirement of SLT have a substantial negative impact on the community of user (CoU) such as educators, scholars, and others who are interested in performing this technology as a tool for their instruction and learning (Abdullah, et al., 2014). As a consequence, CoU must pursue not only to pass on information accuracy, but also to support information availability and relevance as it pertains to the effectiveness of SLT on students' performance in statistics. Thus, the driving evidence of the study is that the evolution of student's performance can be achieved mostly through a common standard infrastructure requirement of data quality in helping the $\mathrm{CoU}$ for statistical information to be successful in obtaining, storing, distributing and using the statistical data for their particular use.

DeLone and McLean (1992) have placed information system success (IS) model as a multifaceted construct consists of quality measures (system, service, and information quality), attitudinal outcomes (employment and satisfaction), and performance-related issues (individual and organisational impacts). By considering the base requirement of information quality model of SLT as the direction in fostering the information of best practice among the $\mathrm{CoU}$, it can also ameliorate the quality of their work to the quality of the statistical data application in higher education system environment (Abdullah et al., 2014). Beyond, despite the vast literature on IS success model in the context of education, there are still little empirical evidence which relate the information systems quality variables directly and indirectly with the academic performance in Malaysian setting (e.g., Bin Masrek, 2007; Nor Fadilah et al., 2013). Therefore, the aim of this study is to examine the DeLone and McLean Information systems (IS) success model as a framework to evaluate the direct and indirect effect of SLT on the performance of graduates in statistics class.

\section{Theoretical Framework and Hypothesis Testing}

In the present paper, we displayed the DeLone and McLean (1992) Information systems (IS) success model as a framework for assessing positive effect of SLT on the performance of graduate students in a statistics course. This model offers a strong indicator of the success of the information systems by recognising six consistent dimensions of the IS success: systems quality, information quality, service quality, intention to use, user satisfaction, and net benefits as shown in Figure 1.

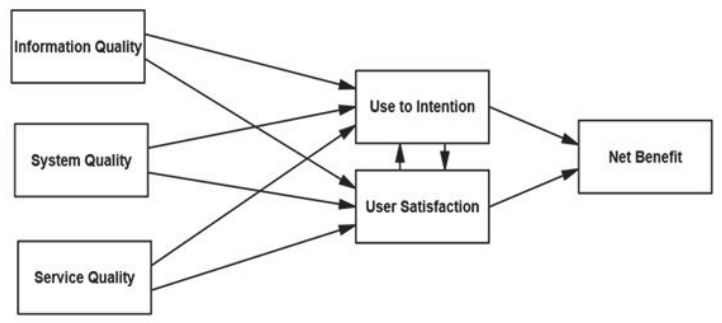

Figure 1. Revised model of information systems success (DeLone \& McLean, 2003). 
These variables are very common to the variables of IS success in the DeLone and Mclean success model. However, many studies have attempted to extend the DeLone and Mclean original IS success model (e.g., Rai, Lang, \& Welker, 2002). Some have done so to overwhelm the inadequacies of the use of construct by DeLone and Mclean, while other researchers have done so to suit the situation with their studies. For instance, some of the current investigations have validated the IS success models in the setting of education. Rai et al. (2002) validated two models of IS success, DeLone and McLean (1992) and Seddon (1997), with the student uses combined student information system. The study employed five variables (system quality, information quality, perceived usefulness, user satisfaction, and IS use) to examine the models at individual level. The study found that both IS success models revealed an acceptable fit to the data. In other study, Nor Fadilah et al. (2013) considered the significant issues that are influencing learners' satisfaction in blended learning (BL) based on the related constructs of D\&M IS Model. The results of the study displayed that the system quality, service quality, and information quality are the most significant factors that will influence student's satisfaction in BL. When the students are satisfied with this method of learning, it will lead to intention to use. It is our purpose to study further the profits that the students will get, in this case the students' final score in the course. These five factors described a total of 79.02 percent of the variance with 0.958 of Cronbach's Alpha reliability test.

Another study was completed by Machado-Da-Silva, et al., (2014). The study exhibited the relations between the system quality, service quality, and information quality regarding student's satisfaction and employment of systems in virtual learning environments using the e-learning success model improved by Holsapple and Lee-Post (2010) from DeLone and McLean $(1992,2003)$ model as a theoretical origin. The study was carried out by means of an online programme proposed to 291 students from public and private organisations from numerous areas in Brazil. The results demonstrated that the variations in system quality, information quality, and service quality affect the use of the system, and the user satisfaction construct had $89 \%$ of the variance explained by information quality and service quality. Many of the advantages of distance learning programmes are associated with students' satisfaction and their intensity in using the learning system. By extending the IS success model, bin Masrek (2007) assessed the efficacy or the success of universities' portal implementation from the viewpoint of students as users. The findings presented that IS effectiveness on elements containing service quality and systems quality are significantly correlated with user satisfaction. The study also discovered that out of the three predictors investigated, only attitudes towards the portal were found to be significantly correlated with the IS effectiveness dimensions.

By reviewing past studies, many of these studies have validated the original model and its interrelationships while different studies have advocated the improvements to the first model. Based on these contributions, we suggest a renewed IS success model to serve as a basis for the placing and compare it with the IS experimental research. The model must continue to be examined and argued. By approaching the SLT as an information system, the updated model as displayed in Figure 1 can be used to measure the success of SLT application. It indicates that the success of SLT can be placed into a broader viewpoint instead of being constrained only by its use. The explanation for the adaptation of the model was based on the fact that this study tries to use a high profile IS model such as the IS Success Model as a lens to verify the success of statistics course using SLT. Thus, six constructs were recognised in the present study consists of system quality, information quality, and service quality as independent constructs, user satisfaction and intention to use as mediating constructs, and student performance as a dependent construct to validate the IS success model on the effectiveness of SLT on students' performance in statistics course.

\subsection{Student Statistic Performance}

Net benefits serve as a final measure of IS success in earlier IS success models (e.g., DeLone \& McLean, 2003; Seddon, 1997). DeLone and McLean (2003) suggested that net benefits indicate the ultimate influence of the system for its participants. Seddon (1997) insisted that diverse stakeholders may have different opinions about what is beneficial to them. Thus, when determining the net advantages of an IS, researchers need to define naturally and carefully the stakeholders and the setting of the net benefits that are going to be determined (DeLone \& McLean, 2003). In the learning system framework, numerous scholars (Eom, et al., 2012) have discussed the educational/learning outcomes (e.g. individual impacts such as class work/test performance) as the measures of success. Following the propositions of prior researchers, this study concentrates on the SLT users as the stakeholders, and therefore measures the net benefits from users' (i.e. students') perspective. Consequently, the net benefits in this study represent as learner statistics performance in the context of IS learning. 


\subsection{System Quality and Student Statistic Performance}

System quality was contracted directly from DeLone and McLean (2003) and referred to the data quality components and software quality and to the system components that are affecting the end-user and the way they interact with the system. Consequently, the system quality in this study refers to the execution of the SLT in the statistics course that affects students' performance in statistics according to the way they interact and use the SLT. The quality of the SLT in this study was determined by the degree to which the availability of the system on request-reply time (e.g., the time required to respond to the user's request, e.g., download time), modern technologies (e.g., graphical user interface in operating system), flexibility, data quality, and integration. These are the examples of the types of character that are appraised by users of SLT in statistics class. Aiterature review of the IS success studies also showed that net benefits were influenced by the systematic quality in IS environment (Petter, DeLone, \& McLean, 2008; Urbach \& Müller, 2012). According to Wang (2008), system quality has a positive impact on the intention to reuse IS. Therefore, student users are more likely to continue using SLT because the high information format and high data capacity is positively associated with perceived net benefits in terms of the improvement of student academic performance in a statistics course, so we put forward:

$\mathrm{H} 1$ : System quality towards the SLT is positively linked with student academic performance in a statistics class.

\subsection{Information Quality and Student Statistic Performance}

Information quality in this study is a term which defines the course content of information systems and information format delivered through SLT. Information format assesses the quality of performance of the information and whether the statistical information system via SLT provided is in an easy-going-to-read format. Low-quality or invalid SLT yields lowquality information (regarding the information, content factor) due to unrelated and incorrect/incomplete information. On the other hand, high-quality information in terms of information content and data format can be directed to high net benefits in terms of statistics information support (i.e., anticipating students' needs) and the internal efficiency of individual (i.e., high-quality academic performance in statistics class). Urbach \& Müller (2012) found that information quality had a moderate effect on net benefits. Hence, the study presents the following hypothesis:

$\mathrm{H} 2$ : Information quality towards SLT is positively linked with student academic performance in a statistics class.

\subsection{Service Quality and Student Statistic Performance}

Service quality is debated as the overall support supplied by a service provider or support rendered to the students in the environment. It pertains regardless of whether this support is delivered by the IS department, a new organisational unit or subcontracted to an Internet Service Provider (ISP ; DeLone \& McLean, 2004). In this study, service quality refers to the support provided by the SLT service provider. SLT services will become better when it is aligned with statistics course goals, resulted in an improved quality of statistics course, better anticipation of student's demands, and more reliable services to users linked to statistics. SLT specialists usually assert error-free records and provide honest services to sustain the continuity of successful student's performance in statistics. Urbach and Müller (2012) found that there is a significant relationship between service quality and net benefits. Wang (2008) expressed that service quality has a positive result on the intention to use IS. Thus, student users are more likely to embrace and use the SLT if there are useful supportive functions from the service providers and adequate funding for IT support unit in a University context. Hence, we postulate that:

H3: Service Quality towards the SLT is positively linked with student academic performance in a statistics class.

\subsection{The Mediating Effects of Intention to Use and User Satisfaction}

The role of satisfaction in intensifying the accomplishment of student's learning or individual academic staff's teaching activities using the SLT is very important. User satisfaction in this present study points to the level of a student user is quenched with his or her general use of SLT under consideration. For a student, the satisfaction resulted from the use of SLT which consists of the developments in the learning result and outcome, decision-making, and the quality of the students are shaped by the university through the SLT. Rai et al., (2002) assess the validity of DeLone and McLean's (1992) and Seddon's (1997) IS success models and found that IS user satisfaction impacts the IS use: a higher level of satisfaction produces bigger necessity of user in the system. Earlier IS studies have also revealed that satisfaction is a significant predictor of the intention to reuse (Petter \& McLean, 2009; Y.-S. Wang, 2008).

Furthermore, the intention to use is known as a significant predictor of the information system used in IS study 
(Davis, Bagozzi, \& Warshaw, 1989; Venkatesh, et al., 2003). Especially if the quality characteristics of the SLT are high, students tend to sense that using the instrument would influence their statistics performance, hence easing the use of the system. Freeze et al., (2010) discovered that learners with a higher level of use/satisfaction are likely to agree that the elearning system has added value to their learning experience (improving their performance in class work). DeLone and McLean (2003) proposed that, because of the system use and user satisfaction, a particular net benefit will occur from the viewpoint of the stakeholder system. Moreover, based on the IS/educational technology success literature (Chen, 2010; DeLone \& McLean, 2003; Lin \& Wang, 2012; H.-C. Wang \& Chiu, 2011; Y.-S. Wang, 2008) and the theory of planned behaviour (Ajzen, 1991), satisfaction and intention to use are usually modelled as mediating factors in determining information system acceptance by users in IS fields (Ajzen, 1991; Brady \& Robertson, 2001; Dabholkar, Shepherd, \& Thorpe, 2000; Rai et al., 2002; Zviran \& Erlich, 2003). Therefore, we anticipate the intention to use and user satisfaction mediate the effects of predictor variables on student performance as follows:

$\mathrm{H} 4$ : The intention to use and user satisfaction mediates the relationship between predictor variables and student academic performance in a statistics class.

H4a: System quality towards SLT will have an indirect effect on statistical performance through the intention to use and user satisfaction.

H4b: Information quality towards SLT will have an indirect effect on statistical performance through the intention to use and user satisfaction.

H4c: Service quality towards SLT will have an indirect effect on statistical performance through the intention to use and user satisfaction.

\section{Research Methods}

In this study, a quantitative approach was used, by which data were accumulated by the means of self-administered survey. Participants were drawn from 129 students enrolled in Statistics for Social Science course and was taught by the author in 2012 at UPM, located in Malaysia. To get reliable results in structural equation modeling (SEM), Kline (2005) suggested to use a sample size of 100-150 cases. The sample size for this study was 129 and thus met the recommended guidelines. A stratified sampling technique was employed to affirm the respondents were well meant by several groups. The primary criterion for the respondents was that they had used the SLT software for at least one semester. This criterion was imperative; as it guarantees that the selected students take in the necessary knowledge about SLT and can interpret the content very quickly.

The survey consisted of 6 constructs and a total of 59 items. The constructs were comprised of student's statistical performance (SP) (11 items), user satisfaction (US) (12 items), intention to use (IU) (6 items), information quality (9 items), system quality (10 items), and service quality (10 items). 5-point was analysed for each of the items that ranged from 1 (always agree) to 5 (always disagree). The results of reliability analysis are presented in Table 1 (See in appendix A). An SEM analysis was employed to examine the relationships between the measures, allowing us to try the entire system of the relationships and to gauge the direct effects (effect of information quality, system quality, and information quality on student statistics performance) and the indirect (mediating) effect of user satisfaction and the intention to use (Kline, 1998; Tanaka et al.,1990). The hypothesized structural equation model was tested using AMOS utilising maximum likelihood estimations. An SEM analysis was done using a measurement model analysis and a structural model analysis (Anderson \& Gerbing, 1988). We examined the significance of the mediated effect using the bias-corrected bootstrap test as recommended by Preacher and Hayes (2008).

\section{Analysis Results}

\subsection{Profile of Respondents}

The participants in the study were diverse in gender, race, qualification pursued, and age. Established with the demographic data, $27.9 \%$ of the respondents were male, whereas $72.1 \%$ of the respondents were female. The outcome indicated that there has been an increment of women's participation in graduate training in Malaysia but the trend is towards statistics. A wide range of races, including Malay $(87.6 \%, n=113)$, Chinese $(6.2 \%, n=8)$, and Indian $(2.3 \%, n$ $=3$ ) were presented in this sample. In addition, $46.2 \%$ of the respondents were pursuing master's programmes while 9.3 $\%$ were Ph.D. students. The mean age of the students was $34.9(n=45)$, with the age ranged between 26 and 30 . 


\subsection{Structural Equation Modeling (SEM)}

The overall form of SEM contains the measurement model and the structural model. Before running these two stages for SEM building, normality test by maximum likelihood estimation is needed to screen the data.

Maximum likelihood estimation is a method used to estimate the models provided. In this work, an assessment of normality displayed the kurtosis which was ranged from -.738 to 1.336 , and the Skewness ranged from -.066 to -.760 in which the data were considered close to normal and the items were usually distributed in the general. Byrne (2010) recommended that if absolute values are between -2 and +2 in Skewness and absolute values are between -7 and +7 in kurtosis, all items can usually be distributed.

\subsubsection{Measurement Model}

The measurement model was examined through confirmatory factor analysis (CFA). CFA is the first level of data preparation of SEM for individual construct which is used to test for model fit, convergent validity, and discriminant validity. For the assessment of model fit, we employed a group of descriptive goodness-of-fit indices. The fit statistics displayed a reasonably good fit for the model with; $\mathrm{X} 2 / \mathrm{DF}=1.603 ; \mathrm{AGFI}=.729, \mathrm{CFI}=.925, \mathrm{NFI}=.867, \mathrm{TLI}=.917, \mathrm{IFI}=.927$, RMSEA $=.068$.

Three criteria were proposed to establish the convergent validity, which all indicator factor loadings should be significant and exceed 0.5; construct reliabilities should exceed 0.70; and average variance extracted (AVE) by each construct should exceed 0.50 . The findings indicated that factor loadings for all 30 items for a given latent construct were significant at $p=0.001$ and greater than 0.5 . Table 2 suggests that since all 6 constructs revealed acceptable composite reliability exceeded 0.70 (the minimum reliability was 0.85 ) and all values of AVE were higher than 0.5 (the minimum AVE was 0.583 ), the convergent validity was demonstrated.

In the next stage, we evaluated the discriminant validity of hypothesized scales based on two criteria suggested by Gefen and Straub (2005). First, AVE should be better than the squared inter-correlations coefficients between the construct and all other variables, and second, the within-construct item loadings should exceed the inter-construct factor loadings by at least 0.10 . The findings of this study showed that the AVEs were ranged from 0.583 to 0.793 and each AVE was much larger than the corresponding squared inter-construct correlations with the exception of InQ-SyQ, SyQInQ, and US-SyQ (See Table 2).

In the latter instance, the correlation between the measures was still considerably .9, eliminated the possibility of multicollinearity (Tabachnick \& Fidell, 2007). Therefore, the measurement model established an adequate reliability, convergent validity, and discriminant validity.

Table 2. Descriptive statistics, reliability, squared correlations, and average variance extracted

\begin{tabular}{lccccccc}
\hline Variable & CR & $\operatorname{InQ}$ & SeQ & SyQ & US & IU & SP \\
\hline Information Quality (InQ) & 0.873 & $(0.583)$ & & & & & \\
System Quality (SeQ) & 0.909 & .55 & $(0.715)$ & & & & \\
Service Quality (SyQ) & 0.896 & .69 & .567 & $(0.591)$ & & & \\
User Satisfaction (US) & 0.910 & .71 & .62 & .69 & $(0.629)$ & & \\
Intention to Use (IU) & 0.910 & 0.319 & .438 & .37 & .52 & $(0.67)$ & \\
Student Statistics Performance (SP) & 0.939 & .40 & .434 & .455 & .55 & .25 & $(0.793)$ \\
\hline
\end{tabular}

Squared correlations are below the diagonal, and AVE estimates presented on the diagonal in parenthesis. $C R=$ construct reliability.

\subsubsection{Structural Model Analysis}

The partial mediation model showed in Figure 2 estimated the direct path from information quality, service quality, and system quality on student statistics performance, and indirect paths stemming from the mediator variables (user satisfaction and intention to use). InQ, SeQ, and SyQ equally explained $58.1 \%(\mathrm{R} 2=0.581$ ) of the variance in SP (Fig. 2). Overall, .809\% of the variance in US was accounted by InQ, SeQ, and SyQ, and .489\% of the variance in IU were accounted by InQ, SeQ, and SyQ. The finding also suggested that the fit indices met the requirements for indirect model. However, the value of GFI in the direct model was under 0.8. Therefore, the fit indices proposed that the model delivered an excellent fit to the data: $\chi^{2} / \mathrm{df}=1.615, \mathrm{P}=.000, \mathrm{CFI}=.922$, GFI= .770, TLI= .914, IFI= .923, RMSEA $=.065$. 
Table 3 indicates the standardized regression weights of the direct and mediated paths and their corresponding pvalue based on bias-corrected methods.

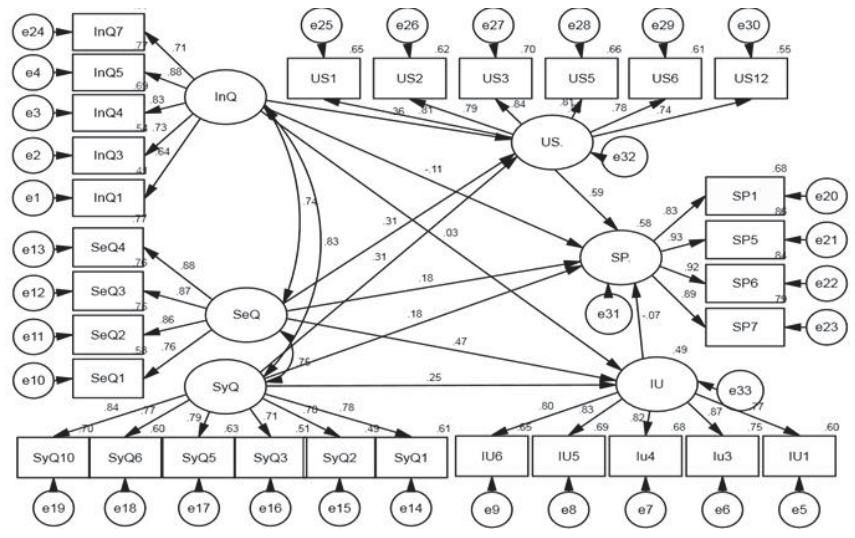

Figure 2. Estimated path coefficients and the percentages of variance explained by partial mediation model

Table 3. Standardized estimation of the direct and indirect effects of information quality, system quality, and information quality on student statistics performance

\begin{tabular}{|c|c|c|c|c|c|c|c|c|}
\hline \multirow{2}{*}{ Variables } & \multicolumn{2}{|c|}{ Direct Model } & \multicolumn{4}{|c|}{ Full Mediation Model } & \multicolumn{2}{|c|}{$\begin{array}{c}\text { Bootstrapping Bias } \\
\text { Corrected } 95 \% \mathrm{Cl}\end{array}$} \\
\hline & $\beta$ & $\rho$ & $\beta$ & $\rho$ & SIE & $\rho$ & $\begin{array}{c}\text { Lower } \\
\text { limit }\end{array}$ & $\begin{array}{c}\text { Upper } \\
\text { limit }\end{array}$ \\
\hline $\ln Q \rightarrow \mathrm{SP}$ & .114 & .483 & -.107 & .532 & .213 & .091 & -.038 & .811 \\
\hline SyQ $\rightarrow$ SP & .340 & $.041^{* *}$ & .184 & .278 & .162 & .179 & -.114 & .694 \\
\hline $\mathrm{SeQ} \rightarrow \mathrm{SP}$ & .319 & $.012^{* *}$ & .175 & .219 & .146 & 159 & -.068 & .481 \\
\hline
\end{tabular}

The results showed that the direct impact existed only between system quality and student statistics performance $(\beta=$. $340, \rho=.041)$, and service quality and student statistics performance $(\beta=.319, \rho=.012)$. Hence, H1 and H3 were supported by the data. Information quality had insignificant relationship with student statistics performance, hence $\mathrm{H} 2$ was rejected.

In hypothesis $4 \mathrm{a}$, the indirect effect was estimated to test the mediating effect of user satisfaction and intention to use. The association between information quality and statistics performance is presented in Table 2. There was an insignificant direct effect for system service on statistics performance $(\beta=-0.107 / p=.532)$ in the non-existence of the mediators. There was also insignificant indirect effect ( $\beta=.213 / p=091 ; 95 \%$ bootstrap $\mathrm{Cl}$ of -.038 to 0.811 respectively). Therefore, $\mathrm{H} 4 \mathrm{a}$ was not supported. $\mathrm{H} 4 \mathrm{~b}$ showed that these two mediators were the mediating variables between system quality and student statistics performance. Table 4 displays that the user satisfaction and intention to use did not partially mediate the effect of information quality on student performance in the statistics course ( $\beta=.162$, p/.179; $95 \%$ bootstrap $\mathrm{Cl}$ of -.114 to .694 , respectively), hence, $\mathrm{H} 4 \mathrm{~b}$ was not supported by the data.

In connection with hypothesis 4c, the mediational impact of user satisfaction and intention to use of an association between service quality and student statistics performance was investigated. The results from the bootstrapping analysis, as illustrated in Table 4 did not prove the indirect effect on PEoU and student statistics performance $(\beta=.146$, pl159; 95 $\%$ bootstrap $\mathrm{Cl}$ of -0.068 to 0.481 , respectively). Therefore, $\mathrm{H} 4 \mathrm{C}$ was not supported.

\section{Discussion}

The study planned to examine the use of SLT among university students in statistics course in the Malaysian setting and focused at Universiti Putra Malaysia. This survey evaluated the success factors for the application of SLT by employing 
the DeLone and McLean's information systems (IS) success model. In the first hypothesis (H1), we tested the immediate issue of system quality on student performance statistics. The findings showed that system quality had a significant direct effect on user statistics performance which was related to earlier studies in knowledge management system context (Petter et al., 2008; Urbach \& Müller, 2012). As stated by Wu and Wang (2006), system quality may be vital at the first stage of applying IS. It means that those students perceived the SLT's system quality delivered by the designer as excellent. In other words, it appeared that students believe that SLT is beneficial. These findings were consistent with Liaw (2008) in which he stated in his work that while using the learning tool system, the students indicated that they required more interactive system that was easier to use, and more accessible, user friendly, and consistent. Based on the second hypothesis ( $\mathrm{H} 2)$, the study results showed that information quality was an insignificant predictor of university student performance in the statistics course. The indications were that users were not satisfied with the information quality provided by SLT, which influenced them to not employ the SLT. It means that the students perceived the information delivered by SLT as not supportive in providing responses throughout learning. From the information provided by SLT students, they were not able to intensify and strengthen the information learned in lectures. These findings were inconsistent with the results in previous IS studies (Petter et al., 2008; Petter \& McLean, 2009; Urbach \& Müller, 2012), therefore there is a requirement to improve the information delivered by the SLT for users to enhance their achievement in statistics. For example, system developers can utilise the measures of the information quality to key out the failings of the current SLT, recognising the instructional or technological parts that can be an additional progress to improve learning performance. Regarding the detection of quality weaknesses, it delivers the base for emerging corresponding action plans to improve them. In particular, they can use it for participant's design to compare the levels of learning performance among students by the previous version of the system and those by the updated system. Furthermore, consistency, assurance, receptiveness, and sympathy of instructors do contribute to the strong effect of service quality on the perceived of SLT between users. The SLT can be used as a way to disseminate information and engage the users while visiting the website, thereby influences them to use the SLT continually effectively. Based on the empirical findings related to IS success model, the lecturer can concentrate on the quality of SLT service to effectively intensify student satisfaction, which then leads to the intention for future use of SLT. In other terms, any subjects linked to the system quality may be compensated by having a good service quality in the SLT context. Lastly, students with intrinsic aim are well interested in the SLT usage in the statistics course.

In hypotheses $4 \mathrm{a}, 4 \mathrm{~b}$, and $4 \mathrm{c}$, there were hypothesized relationships between three IS constructs and statistics performance that would be mediated by the user satisfaction and intention to use in the reformed statistic course activities through SLT which would, in turn, lead to higher levels of statistics performance. Our findings did not provide the proof of indirect effect of these three IS constructs on university students performance in statistics class and also indicate the irrelevance of the hypotheses associated with IS success model research.

\section{Conclusion}

The survey was based on the Information systems (IS) success model originated by DeLone and Mclean in 2003 as the theoretical basis for evaluating the direct and indirect effect of quality of SLT software on the performance of university students in statistics class. The four hypotheses in the study were grounded and justified by prior empirical studies of information success (IS) studies and determining organisations. The evidence supported hypotheses 1 and 3 and did not confirm the strength of indirect model which improved the IS success model through some mediation effects (i.e., intention to use and user satisfaction). The $58.1 \%$ of overall clarifying abilities was showed in the validated research model, similarly appeared to the potential of the information systems (IS) success model for evaluating the success of the SLT in Malaysian context. The study holds few implications for system developers and educators to support the critical issues for the apprehension of SLT in reformed statistics course in higher education. As established in the results of the survey, they should offer better services and training courses to encourage students and future practitioners to acquire and use the SLT in their learning statistics. Hence, the framework and the outcomes of this study may encourage the practices and future studies in statistics education.

\section{References}

Abdullah, R., Samah, B. A., Bolong, J., D'Silva, J. L., \& Shaffril, H. A. M. (2014). Infrastructure requirement of knowledge management system model of statistical learning tool (SLT) for education community (Vol. 1613, pp. 188-194). Presented at the Statistics and Operational Research International Conference, AIP Publishing. Retrieved from http://scitation.aip.org/content/aip/proceeding/ aipcp/10.1063/1.4894345 
Ajzen, I. (1991). The theory of planned behavior. Organizational Behavior and Human Decision Processes, 50(2), 179-211.

Anderson, J. C., \& Gerbing, D. W. (1988). Structural equation modeling in practice: A review and recommended two-step approach. Psychological Bulletin, 103(3), 411.

Bin Masrek, M. N. (2007). Measuring campus portal effectiveness and the contributing factors. Campus-Wide Information Systems, 24(5), 342-354.

Brady, M.-K., \& Robertson, C.-J. (2001). Searching for a consensus on the antecedent role of service quality and satisfaction: an exploratory cross-national study. Journal of Business Research, 51(1), 53-60.

Byrne, B. M. (2010). Structural equation modeling with AMOS; basic concepts, applications, and programming (2nd ed.). New York/London: Taylor \& Francis.

Chen, R.-J. (2010). Investigating models for preservice teachers' use of technology to support student-centered learning. Computers \& Education, 55(1), 32-42.

Dabholkar, P. A., Shepherd, C. D., \& Thorpe, D. I. (2000). A comprehensive framework for service quality: An investigation of critical conceptual and measurement issues through a longitudinal study. Journal of Retailing, 76(2), 139-173.

Davis, F. D., Bagozzi, R. P., \& Warshaw, P. R. (1989). User acceptance of computer technology: A comparison of two theoretical models. Management Science, 35(8), 982-1003.

DeLone, W. H., \& McLean, E. R. (1992). Information systems success: the quest for the dependent variable. Information Systems Research, 3(1), 60-95.

DeLone, W. H., \& McLean, E. R. (2003). The DeLone and McLean model of information systems success: A tenyear update. Journal of Management Information Systems, 19(4), 9-30.

DeLone, W. H., \& McLean, E. R. (2004). Measuring e-commerce success: Applying the DeLone \& McLean information systems success model. International Journal of Electronic Commerce, 9(1), 31-47.

Eom, S., Ashill, N. J., Arbaugh, J. B., \& Stapleton, J. L. (2012). The role of information technology in e-learning systems success. Human Systems Management, 31(3), 147-163.

Freeze, R. D., Alshare, K. A., Lane, P. L., \& Wen, H. J. (2010). IS success model in e-learning context based on students' perceptions. Journal of Information Systems Education, 21(2), 173.

Gefen, D., \& Straub, D. (2005). A practical guide to factorial validity using PLS-Graph: Tutorial and annotated example. Communications of the Association for Information Systems, 16(1), 5.

Holsapple, C. W., \& Lee-Post, A. (2010). Behavior-based analysis of knowledge dissemination channels in operations management. Omega, 38(3), 167-178.

Kline, R. B. (1998). Principles and practice of structural equation modelling. New York, NY: Guilford Press.

Kline, R. B. (2005). Principles and practice of structural equation modeling. New York, NY: The Guilford Press.

Liaw, S.-S. (2008). Investigating students' perceived satisfaction, behavioral intention, and effectiveness of e-learning: A case study of the Blackboard system. Computers \& Education, 51(2), 864-873.

Lin, W.-S., \& Wang, C.-H. (2012). Antecedences to continued intentions of adopting e-learning system in blended learning instruction: A contingency framework based on models of information system success and task-technology fit. Computers \& Education, 58(1), 88-99.

Machado-Da-Silva, F. N., de Souza Meirelles, F., Filenga, D., \& Brugnolo Filho, M. (2014). Student Satisfaction Process in Virtual Learning System: Considerations Based In Information And Service Quality from Brazil's Experience. Turkish Online Journal of Distance Education, 15(3). Retrieved from https://tojde.anadolu.edu.tr/tojde57/pdf/article_11.pdf

Marshall, J. M. (2002). Learning with technology: Evidence that technology can, and does, support learning. San Diego, CA: San Diego State University.

Moore, D. S. (1992). What is statistics? In Perspectives on Contemporary Statistics (pp. 1-18). Washington D.C: Mathematical Association of America.

Moore, D. S. (1997). New pedagogy and new content: The case of statistics. International Statistical Review, 65(2), 123-137.

Nor Fadilah, T., Rashidah, M., Nur Huda, J., Nur Diana, Z., Safura Adeela, S., \& Zuriati, I. (2013). Students' satisfaction on blended learning: The use of factor analysis. Presented at the 2013 IEEE Conference on e-Learning, e-Management and e-Services, Sarawak, Malaysia.

Onwuegbuzie, A. J. (1998). Statistics anxiety: A function of learning style. Research in the Schools, 5(1), 43-52.

Petter, S., DeLone, W., \& McLean, E. (2008). Measuring information systems success: models, dimensions, measures, and interrelationships. Journal of Information Systems, 17(3), 236-263.

Petter, S., \& McLean, E. R. (2009). A meta-analytic assessment of the DeLone and McLean IS success model: An examination of IS success at the individual level. Information \& Management, 46(3), 159-166.

Preacher, K., \& Hayes, R. F. (2008). Asymptotic and resampling strategies for assessing and comparing indirect effects in multiple mediator models. Behavior Research Methods, 40(3), 879-891.

Rai, A., Lang, S. S., \& Welker, R. B. (2002). Assessing the validity of IS success models: An empirical test and theoretical analysis. Information Systems Research, 13(1), 50-69.

Rossman, A., \& Chance, B. (2004). A data-oriented, active-learning, post-calculus introduction to statistical concepts, applications, and theory. In G. Burrill \& M. Camden (Eds.), Proceedings of IASE 2004 Roundtable on Curricular Development in Statistics Education. Lund, Sweden. Voorburg: The Netherlands: International Statistical Institute.

Seddon, P. B. (1997). A respecification and extension of the DeLone and McLean model of IS success. Information Systems Research, 
8(3), 240-253.

Tabachnick, B. G., \& Fidell, L. S. (2007). Using Multivariate Statistics: Pearson Education Inc. Boston, MA: Allyn and Bacon.

Tanaka, J. S., Panter, A. T., Winborne, W. C., \& Huba, G. J. (1990). Theory testing in personality and social psychology with structural equation models: A primer in 20 questions. In C. Hendrick \& M. S. Clark (Eds.), Research methods in personality and social psychology (pp. 217-242). Newbury Park, CA: Sage. Retrieved from http://psycnet.apa.org/psycinfo/1990-97262-009

Urbach, N., \& Müller, B. (2012). The updated DeLone and McLean model of information systems success. In Y. K. Dwivedi \& et al. (Eds.), Information Systems Theory: Explaining and Predicting 1 Our Digital Society (Vol. 1, pp. 1-18). Springer.

Venkatesh, V., Morris, M. G., Davis, G. B., \& Davis, F. D. (2003). User acceptance of information technology: Toward a unified view. MIS Quarterly, 27(3), 425-478.

Wang, H.-C., \& Chiu, Y.-F. (2011). Assessing e-learning 2.0 system success. Computers \& Education, 57(2), 1790-1800.

Wang, Y.-S. (2008). Assessing e-commerce systems success: a respecification and validation of the DeLone and McLean model of IS success. Information Systems Journal, 18(5), 529-557.

Wu, J.-H., \& Wang, Y.-M. (2006). Measuring KMS success: A respecification of the DeLone and McLean's model. Information \& Management, 43(6), 728-739.

Yahaya, A., \& et al. (2007). Menguasai penyelidikan dalam pendidikan: teori, analisis dan interpretasi data. Batu Caves, Selangor: PTS Professional Publishing Sdn. Bhd.

Zviran, M., \& Erlich, Z. (2003). Measuring IS user satisfaction: review and implications. Communications of the Association for Information Systems, 12(1), 5.

\section{Appendix A}

Table 1: Question items used in this study

\begin{tabular}{|c|c|c|c|}
\hline Constructs & Item & Measure & $\begin{array}{c}\text { Reliability } \\
\text { (Cronbach } \\
\text { Alpha } \alpha \text { ) }\end{array}$ \\
\hline Service Quality (SeQ) & $\begin{array}{l}\text { SeQ1 } \\
\text { SeQ2 } \\
\text { SeQ3 } \\
\text { SeQ4 } \\
\text { SeQ5 } \\
\text { SeQ6 } \\
\text { SeQ7 } \\
\text { SeQ8 } \\
\text { SeQ9 } \\
\text { SeQ10 }\end{array}$ & $\begin{array}{l}\text { The quality of the resulting analysis is satisfactory SLT } \\
\text { SLT is user-friendly } \\
\text { SLT is a learning tool that is reactive } \\
\text { SLT is a reliable learning tool'. } \\
\text { SLT analysis the is latest analysis tool I've been employing } \\
\text { SLT can apply anywhere } \\
\text { SLT offers users many benefits } \\
\text { SLT used in the teaching process according to statistics } \\
\text { SLT accelerates the process of learning statistics } \\
\text { SLT helps to increase understanding of statistics }\end{array}$ & .889 \\
\hline System Quality (SyQ) & $\begin{array}{l}\text { SyQ1 } \\
\text { SyQ2 } \\
\text { SyQ3 } \\
\text { SyQ4 } \\
\text { SyQ5 } \\
\text { SyQ6 } \\
\text { SyQ7 } \\
\text { SyQ8 } \\
\text { SyQ9 } \\
\text { SyQ10 }\end{array}$ & $\begin{array}{l}\text { SLT is easy to apply } \\
\text { SLT has an attractive appearance } \\
\text { It is too easy to insert data in SLT } \\
\text { SLT has a very interesting chart } \\
\text { I easily interact with the system } \\
\text { SLT free from harassment } \\
\text { SLT is open access without authority } \\
\text { SLT is easily approachable } \\
\text { SLT is available in a vibrant color to create an appealing appearance } \\
\text { Facility programme is easy borrowing }\end{array}$ & .911 \\
\hline Information Quality (InQ) & $\begin{array}{l}\text { InQ1 } \\
\text { InQ2 } \\
\text { InQ3 } \\
\text { InQ4 } \\
\text { InQ5 } \\
\text { InQ6 } \\
\text { InQ7 } \\
\text { InQ8 } \\
\text { InQ9 }\end{array}$ & $\begin{array}{l}\text { Answers given in the SLT is right } \\
\text { Answers provided in the SLT is complete } \\
\text { The amount of information content } \\
\text { Answers provided in the SLT is consistent } \\
\text { The answer gives in the relevant SLT } \\
\text { SLT is safe to use } \\
\text { The analysis results from the SLT is easy } \\
\text { Information provided by SLT is compatible with learning } \\
\text { I need information content SLT to help learning }\end{array}$ & .891 \\
\hline $\begin{array}{l}\text { Student statistics } \\
\text { performance (SP) }\end{array}$ & $\begin{array}{l}\text { SP1 } \\
\text { SP2 } \\
\text { SP3 } \\
\text { SP4 } \\
\text { SP5 } \\
\text { SP6 } \\
\text { SP7 } \\
\text { SP8 } \\
\text { SP9 } \\
\text { SP10 } \\
\text { SP11 }\end{array}$ & $\begin{array}{l}\text { By using SLT, it helps in bettering my skills and skills related summation notations } \\
\text { By using SLT, it helps in bettering my skills and skills related MCT \& MD } \\
\text { By using SLT, it helps in bettering my skills and skills related normal distribution } \\
\text { By using SLT, it helps in bettering my skills and skills related one sample t-test } \\
\text { By using SLT, it helps in bettering my skills and skills related paired sample t-test } \\
\text { By using SLT, it helps in bettering my skills and skills related independent sample t-test } \\
\text { By using SLT, it helps in bettering my skills and skills related analysis of variation } \\
\text { By using SLT, it helps in bettering my skills and skills related Chi-Square } \\
\text { By using SLT, it helps in bettering my skills and skills related Spearman Rho correlation } \\
\text { By using SLT, it helps in bettering my skills and skills related Pearson correlation } \\
\text { By using SLT, it helps in bettering my skills and skills related Simple Linear Regression }\end{array}$ & .921 \\
\hline
\end{tabular}




\begin{tabular}{lll}
\hline User satisfaction (US) & US1 & SLT offers the latest information about statistical analysis \\
& US2 & SLT ability to help learning statistics \\
US3 & SLT provides accurate information needed \\
US4 & SLT can run into learning \\
US5 & SLT offers the results required \\
US6 & Adequacy of the information required \\
US7 & The information provided is accurate SLT \\
US8 & The output of the SLT displays a useful format \\
US9 & The data supplied by the SLT is clear \\
US10 & SLT is user-friendly software \\
US11 & SLT is easy to apply \\
US12 & Through the SLT, I can deliver the information needed very quickly \\
\hline IU1 & I desire to acquire knowledge about the SLT \\
IU2 & I desire more frequent use SLT \\
IU3 & I will go along to use the SLT in learning statistics \\
IU4 & I contrive to use the SLT in my learning statistics \\
IU5 & I intend to use SLT, when it is necessary. \\
IU6 & I will use SLT in the future \\
\hline
\end{tabular}

